\title{
PERAN INOVASI PRODUK MEMEDIASI ORIENTASI PASAR TERHADAP KINERJA PEMASARAN (Studi pada Usaha Mikro, Kecil dan Menengah Pie Susu di Kota Denpasar)
}

\author{
Ni Kadek Nusanti Putri ${ }^{(1)}$ \\ Ni Nyoman Kerti Yasa ${ }^{(2)}$ \\ ${ }^{(1)(2)}$ Fakultas Ekonomi dan Bisnis Universitas Udayana, Bali, Indonesia \\ email: nusantiputri22@yahoo.com
}

\begin{abstract}
ABSTRAK
Penelitian ini bertujuan untuk mengetahui pengaruh orientasi pasar terhadap kinerja pemasaran yang dimediasi dengan inovasi produk. Penelitian ini berlokasi di Kota Denpasar melibatkan 30 responden yang bertindak sebagai pemilik atau manajer UMKM Pie Susu. Purposive sampling digunakan sebagai metode pengumpulan data. Pengumpulan data dilakukan melalui penyebaran kuesioner. Analisis jalur (path analysis) dan uji Sobel adalah teknik analisis data yang digunakan dalam penelitian ini. Hasil yang ditemukan dalam penelitian ini adalah terbukti inovasi produk sebagai variabel mediasi pengaruh orientasi pasar terhadap kinerja pemasaran. Berdasarkan hasil penelitian, dapat disimpulkan dengan dan inovasi produk mampu memediasi secara penuh pengaruh orientasi pasar terhadap kinerja pemasaran.
\end{abstract}

Kata Kunci: orientasi pasar, inovasi produk, dan kinerja pemasaran

\section{ABSTRAK}

This study was headed to ascertain the effect of market orientation towards the marketing performance which mediated by innovation product. This research is conducted in Denpasar City, involving 30 respondents who are owners or managers of Pie Susu SMMEs. Determined by using the purposive sampling method. Data collection is conducted by distributing questionnaires. The data analysis techniques utilized in this research are the path analysis technique and Sobel test. Results of this research have shown evidence that product innovation is able to mediate the influence of market orientation on marketing performance. Based on the results of the study, it can be concluded with and product innovation capable of fully mediating the market influence on marketing.

Keywords: market orientation, product innovation and marketing performance

\section{PENDAHULUAN}

Pasca krisis tahun 1997 hingga tahun 1998 Usaha Mikro, Kecil dan Menengah (UMKM) berkontribusi besar dengan menjaga kestabilan ekonomi, diakibatkan UMKM memiliki kemampuan beradaptasi dari goncangan ekonomi dengan pembukaan lapangan pekerjaan dan pemerataan pendapatan (Sumiati, 2015). Peningkatan jumlah UMKM yang mencapai 8,4 persen dalam kurun waktu 5 tahun, tidak dapat berbanding lurus dengan usianya yang hanya mencapai 5 hingga 10 tahun saja.

Tingkat kunjungan wisatawan mancanegara maupun domestik di Bali yang meningkat sejalan dengan pengembangan kepopulerannya membentuk konsumen-konsumen potensial yang mendorong pengembangan UMKM (Riyaldi dan Kerti, 2016). Sebagian besar jenis UMKM di Kota Denpasar bergerak pada sektor industri makanan sebesar 11.797 unit usaha atau sekitar 5 persen dari keseluruhan UMKM yang berada di Kota
Denpasar (Dinas Perindustrian dan Perdagangan Provinsi Bali, 2015).

Salah satu jenis kuliner yang saat ini mulai berkembang di Pulau Bali, khususnya Kota Denpasar adalah Pie Susu (Rustiarini dan Dwi, 2015). Sejak tahun 1989, usaha Pie Susu sudah mulai memasuki pasar kuliner Bali, namun citra dari produk ini belum dapat setara dengan salak gula pasir dan kacang asin rahayu (traveloka.com, 2017).

Utamaningsih (2016) menyatakan permasalahan yang dihadapi UMKM sebenarnya adalah rendahnya produktivitas pada penciptaan produk baru akibat kurangnya daya kreativitas dan inovatif sehingga kinerja pemasaran tidak berjalan dengan stabil. Konsep kinerja pemasaran didukung dengan banyak faktor mulai dari kesadaran akan pandangan terhadap pasar, kesadaran melakukan strategi yang inovatif, kemampuan untuk mengambil risiko dan orientasi dari proses pembelajaran (Haryanto et al., 2017). 
Orientasi pasar digunakan untuk memberikan gambaran mengenai keinginan konsumen dan pergerakan pesaing sehingga, perusahaan dapat membentuk strategi baru untuk meningkatkan kepuasan pelanggan (Haryanto et al., 2017). Jyoti dan Sharma (2012) menyatakan terjadinya hubungan positif dan signifikan terhadap kinerja pemasaran. Pendapat berbeda dikemukaan oleh Jabeen et al. (2013) orientasi pasar tidak berpengaruh langsung dan signifikan terhadap kinerja sebuah perusahaan.

Menurut Putri dkk. (2016) dibutuhkan inovasi produk untuk memediasi orientasi pasar terhadap kinerja pemasaran, sehingga terjadi hubungan yang lebih kuat. Inovasi bertindak sebagai pemediasi yang memperkuat pengaruh orientasi pasar terhadap kinerja pemasaran sebagai pengukur prestasi penjualan perusahaan (Jabeen et al., 2013).

Fluktuasi kinerja pemasaran UMKM Pie Susu yang tidak sejalan dengan jumlahnya yang semakin meningkat setiap tahun merupakan semua masalah. Berdasarkan kondisi tersebut serta adanya kesenjangan penelitian (research gap) maka, dilakukan penelitian lebih lanjut mengenai orientasi pasar dan inovasi produk UMKM Pie Susu terhadap kinerja pemasaran di Kota Denpasar. Tujuan penelitian ini adalah menguji hubungan dari inovasi produk, orientasi pasar terhadap kinerja pemasaran, dan peran inovasi produk memediasi orientasi pasar terhadap kinerja pemasaran pada UMKM Pie Susu di Kota Denpasar.

Penelitian yang dilakukan Zhang dan Yanling (2010) menunjukkan bahwa inovasi produk dipengaruhi oleh orientasi pasar secara positif dan siginifikan. Kemungkinan untuk mendapat profit akan meningkat bila orientasi pasar dihubungkan dengan inovasi (Jabeen et al., 2013). Inovasi produk sebagai bentuk dari proses pembacaan dari proyeksi kebutuhan konsumen di pasar (Subroto, 2013). Putri, dkk (2016) dalam penelitianya mengenai industri konveksi di Kota Denpasar menemukan bahwa orientasi pasar dapat berpengaruh positif dan signifikan terhadap inovasi produk. Penelitan yang sejalan juga diperoleh oleh Haryanto dkk. (2017) dan Widyantara (2017). Melalui pemaparan kajian empiris diatas, hipótesis penelitian dapat dibangun sebagai berikut:

H1: Orientasi pasar berpengaruh positif dan signifikan terhadap inovasi produk.

Menurut Bakti dan Harniza (2011) dalam penelitian yang dilakukan pada 100 penumpang Lion Air di Kota Jambi, secara keseluruhan orientasi pasar dapat memberikan pengaruh terhadap kinerja pemasaran. Orientasi pasar dapat meningkatkan kinerja perusahaan secara signifikan dan positif dibuktikan dalam penelitian yang dilakukan oleh Ahimbisibwe et al. (2013), Anggraini dkk. (2014), dan Nur et al. (2014). Hasil penelitian yang berbeda dikemukakan oleh Sumiati (2015). Tahun berikutnya penelitian yang dilakukan oleh Zainul et al. (2016) memiliki hasil yang positif. Dari kajian empiris diatas, dapat dibangun hipotesis penelitian sebagai berikut:

$\mathrm{H} 2$ : Orientasi pasar berpengaruh positif dan signifikan terhadap kinerja pemasaran

Inovasi produk berpengaruh positif dan signifikan terhadap kinerja pemasaran pada penelitian yang dilakukan di United Kingdom (Parkman et al., 2012). Penelitian yang sejalan juga dikemukakan oleh Chaston dan Scoot (2012), berbeda dengan penelitian yang dilakukan oleh Quantsnanda dan Bambang (2015) menyatakan inovasi tidak dapat berpengaruh secara signifikan terhadap kinerja dari pemasaran. Penelitian berikutnya dilakukan oleh Riyaldi dan Kerti (2016) menemukan hasil bahwa inovasi produk berpengaruh positif dan signifikan terhadap kinerja pemasaran. Carvalho dan Joel (2016), Utamaningsih (2016), dan Vera dan Giantari (2016) melakukan penelitian serupa dan memiliki hasil yang sejalan dengan penelitian terdahulu. Berdasarkan kajian empiris diatas, dapat dibangun hipotesis penelitian sebagai berikut:

H3: Inovasi produk berpengaruh positif dan signifikan terhadap kinerja pemasaran.

Theohararkis dan Hooley (2008) juga menyatakan inovasi merupakan hasil dari proses pembelajaran yang bertujuan untuk memperkuat hubungan dari orientasi pasar terhadap kinerja pemasaran. Orientasi pasar tidak dapat memiliki hubungan langsung yang positif dan signifikan terhadap kinerja pemasaran dikemukakan oleh Jhonson et al. (2009). Penelitian lain yang bernilai positif juga dikemukakan oleh Putri dkk. (2016). Berdasarkan kajian empiris diatas, dapat dibangun hipotesis penelitian.

H4: Inovasi produk mampu memediasi secara penuh pengaruh orientasi pasar terhadap kinerja pemasaran

Berdasarkan hipotesis yang telah diaparkan, penelitian ini menggunakan kerangka konseptual sebagai berikut: 


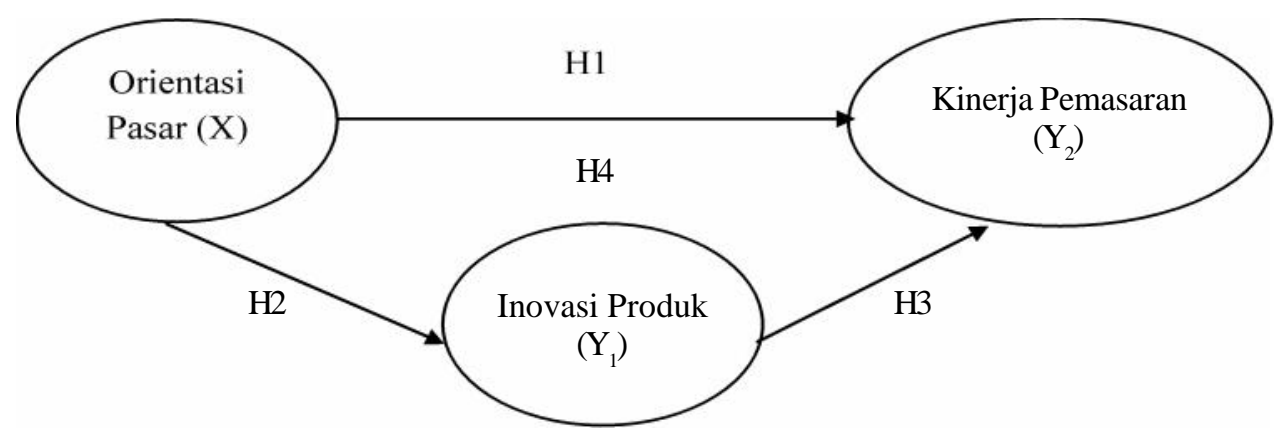

Gambar 1. Kerangka Konseptual

\section{METODE PENELITIAN}

Penelitian ini merupakan penelitian kuantitatif yang bersifat kausal (sebab akibat). Lokasi penelitian ini adalah Kota Denpasar, karena bertindak sebagai pusat kota dan daerah yang memiliki jumlah UMKM terbesar di Bali menurut data Dinas Perindustrian dan Perdagangan Provinsi Bali tahun 2015. Tabel 1 menunjukkan indikator dari setiap variabel. Variabel independent dalam penelitian ini adalah orientasi pasar, variabel intervening adalah inovasi produk dan variabel dependent adalah kinerja pemasaran.

Tabel 1. Klasifikasi Variabel dan Indikator Penelitian

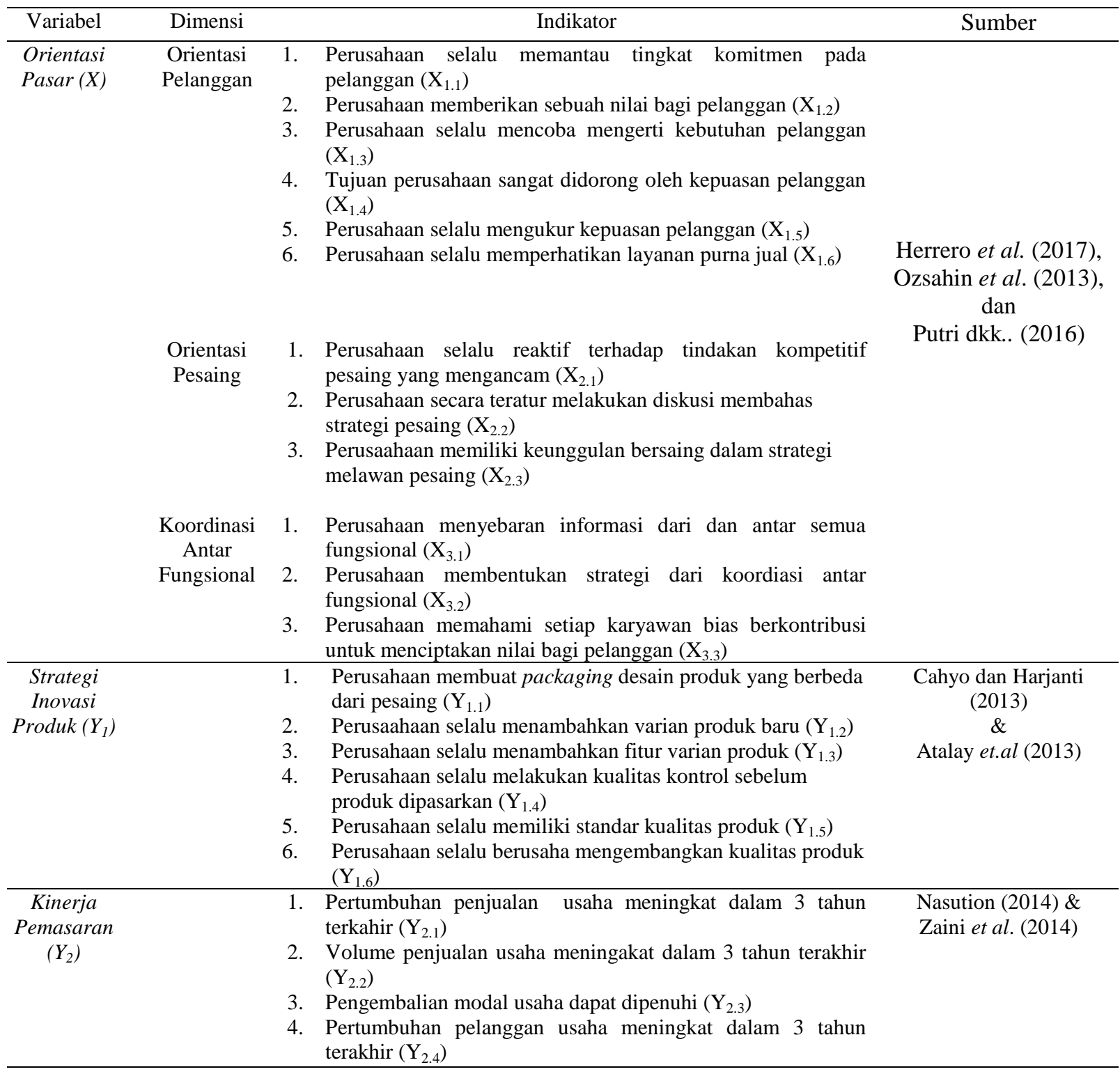


Penelitian ini menggunakan teknik pengambilan sampel dengan purposive sampling dilakukan dengan penyebaran kuesioner yang dinilai dengan skala Likert. Analisis jalur (Path Analysis) dan Uji Sobel digunakan sebagai teknik analisis.

\section{HASIL DAN PEMBAHASAN}

Penelitian ini menggunakan 30 sampel dari pemilik atau manager dari UMKM Pie Susu di Kota Denpasar. Profil dari responden dapat diklasifikasikan berdasarkan varibel demografi seperti jenis kelamin, usia, dan tingkat pendidikan terakhir.

Tabel 2 Profil Responden

\begin{tabular}{ccccc}
\hline No & Variabel & Klasifikasi & Jumlah & Presentase (\%) \\
\hline 1 & Jenis Kelamin & Pria & 18 & $60 \%$ \\
& Wanita & 12 & $40 \%$ \\
\hline 2 & Jumlah & 30 & $100 \%$ \\
\hline & Usia & $20-30$ & 13 & $43 \%$ \\
& $31-40$ & 12 & $40 \%$ \\
& & $41-50$ & 4 & $13 \%$ \\
\hline 3 & Jumlah & 1 & $3 \%$ \\
\hline & Pendidikan Terakhir & SMA & 13 & $100 \%$ \\
& & Diploma & 8 & $43 \%$ \\
& & S1 & 9 & $30 \%$ \\
\hline & S2/ S3 & 0 & $0 \%$ \\
\hline Sumlah & & 30 & $100 \%$
\end{tabular}

Sumber: Data Primer, 2017

Berdasarkan Tabel 2, variabel demografi pada jenis kelamin didominasi oleh pria sebesar 18 orang atau sekitar 60 persen. Usia dari responden sebagian besar berada pada usia 20-30 tahun. Sedangkan, pada tingat pendidikan terakhir responden berada pada SMA sebesar 43 persen. Kuesoner yang disebarkan pada 30 responden dan diuji tingkat kelayakannya menggunakan uji validitas dan reliabilitas.

Tabel 3 Uji Validitas

\begin{tabular}{|c|c|c|c|c|c|}
\hline No & Variabel & Dimensi & Instrumen & $\begin{array}{c}\text { Koefisien } \\
\text { Korelasi }\end{array}$ & Keterangan \\
\hline \multirow{12}{*}{1} & \multirow{12}{*}{$\begin{array}{l}\text { Orientasi } \\
\text { Pasar (X) }\end{array}$} & \multirow{6}{*}{ Orientasi Pelanggan } & $X_{1,1}$ & 0,816 & Valid \\
\hline & & & $\mathrm{X}_{1,2}$ & 0,784 & Valid \\
\hline & & & $\mathrm{X}_{1,3}$ & 0,860 & Valid \\
\hline & & & $\mathrm{X}_{1,4}$ & 0,721 & Valid \\
\hline & & & $\mathrm{X}_{1,5}$ & 0,726 & Valid \\
\hline & & & $\mathrm{X}_{1,6}$ & 0,755 & Valid \\
\hline & & \multirow{3}{*}{ Orientasi Pesaing } & $\mathrm{X}_{2,1}$ & 0,923 & Valid \\
\hline & & & $X_{2,2}$ & 0,836 & Valid \\
\hline & & & $X_{2,3}$ & 0,804 & Valid \\
\hline & & \multirow[t]{3}{*}{ Koordinasi Antar Fungsional } & $\mathrm{X}_{3,1}$ & 0,892 & Valid \\
\hline & & & $X_{3,2}$ & 0,886 & Valid \\
\hline & & & $X_{3,3}$ & 0,942 & Valid \\
\hline \multirow{7}{*}{2} & \multirow{7}{*}{$\begin{array}{c}\text { Inovasi } \\
\text { Produk }\left(\mathrm{Y}_{1}\right)\end{array}$} & Packaging Desain Produk & & 0,895 & Valid \\
\hline & & Penambahan Varian Produk & & 0,721 & Valid \\
\hline & & Penambahan Vitur Varian & & 0,864 & Valid \\
\hline & & Produk & & & \\
\hline & & Kontrol Kualitas & & 0,871 & Valid \\
\hline & & Standar Kualitas & & 0,769 & Vaid \\
\hline & & Pengembangan Kualitas & & 0,831 & Valid \\
\hline \multirow[b]{4}{*}{3} & \multirow{4}{*}{$\begin{array}{c}\text { Kinerja } \\
\text { Pemasaran } \\
\left(\mathrm{Y}_{2}\right)\end{array}$} & Pertumbuahan Penjualan & & 0,826 & Valid \\
\hline & & Volume Penjualan & & 0,872 & Valid \\
\hline & & Return of Asset & & 0,835 & Valid \\
\hline & & Pertumbuhan Pelanggan & & 0,855 & Valid \\
\hline
\end{tabular}

Sumber: Data Primer, 2017 
Table 3 menunjukkan nilai dari koefisien korelasi masing-masing instrument. Besar koefisien korelasi pada setiap indikator $\geq 0,3$ sehingga instrument dinyatakan valid untuk digunakan.

Tabel 4 Hasil Uji Reliabilitas

\begin{tabular}{ccccc}
\hline No & Variabel & Dimensi & Alpha Cronbach & Keterangan \\
\hline 1 & Orientasi Pasar $(\mathrm{X})$ & Orientasi Pelanggan & 0,868 & Reliabel \\
& & Orientasi Pesaing & 0,816 & Reliabel \\
& & Koordiasi Antar & 0,891 & Reliabel \\
& & Fungsional & 0,899 & Reliabel \\
\hline 2 & Inovasi Produk $\left(\mathrm{Y}_{1}\right)$ & & 0,867 & \\
\hline 3 & Kinerja Pemasaran & & & \\
& $\left(\mathrm{Y}_{2}\right)$ & & & \\
\hline
\end{tabular}

Sumber: Data diolah, 2017

Hasil pada Tabel 4 menunjukkan semua nilai dari koefisien Alpha Cronbach. Hasil pengujian menunjukkan nilai Alpha Cronbach setiap variabel $\geq 0,6$. Maka seluruh indikator yang digunakan memenuhi syarat dan konsistensi keandalan data.

Data dari setiap jawaban responden pada kuesioner akan menggambarkan nilai dari setiap variabel yang ada di dalam penelitian ini. Rata - rata skor jawaban responden pada kuesioner dikelompokkan kedalam 5 kelas interval (Wirawan, 2002:35).

Orientasi pasar sebagai variabel independent diukur dengan menggunakan 3 indikator. Hasil dari pengukuran variabel orientasi pasar disajikan dalam Tabel 5 sebagai berikut.

Tabel 5 Penilaian Responden Terhadap Variabel Orientasi Pasar

\begin{tabular}{|c|c|c|c|c|c|c|}
\hline \multirow[t]{2}{*}{ Indikator } & \multicolumn{5}{|c|}{ Distribusi Jawaban $(\%) ; \mathrm{n}=30$} & \multirow{2}{*}{$\begin{array}{l}\text { Rata-Rata } \\
\text { Skor }\end{array}$} \\
\hline & 1 & 2 & 3 & 4 & 5 & \\
\hline \multicolumn{7}{|l|}{ Orientasi pelanggan $\left(\mathrm{X}_{1}\right)$} \\
\hline $\begin{array}{l}\text { Perusahaan selalu memantau tingkat komitmen pada } \\
\text { pelanggan }\left(\mathrm{X}_{1.1}\right)\end{array}$ & 0,00 & 3,33 & 20,00 & 33,33 & 43,33 & 4,17 \\
\hline Perusahaan memberikan sebuah nilai bagi pelanggan $\left(\mathrm{X}_{1,2}\right)$ & 0,00 & 0,00 & 16,67 & 30,00 & 53,33 & 4,37 \\
\hline $\begin{array}{l}\text { Perusahaan selalu mencoba mengerti kebutuhan pelanggan } \\
\left(\mathrm{X}_{1,3}\right)\end{array}$ & 0,00 & 6,67 & 23,33 & 23,33 & 46,67 & 4,10 \\
\hline $\begin{array}{l}\text { Tujuan perusahaan sangat didorong oleh kepuasan } \\
\text { pelanggan }\left(\mathrm{X}_{1,4}\right)\end{array}$ & 0,00 & 3,33 & 26,67 & 43,33 & 26,67 & 3,93 \\
\hline Perusahaan selalu mengukur kepuasan pelanggan $\left(\mathrm{X}_{1,5}\right)$ & 0,00 & 0,00 & 26,67 & 40,00 & 33,33 & 4,07 \\
\hline Perusahaan selalu memperhatikan layanan purna jual $\left(\mathrm{X}_{1,6}\right)$ & 0,00 & 0,00 & 13,33 & 40,00 & 46,67 & 4,33 \\
\hline $\mathrm{X}_{1}$ & & & & & & 4,16 \\
\hline \multicolumn{7}{|l|}{ Orientasi pesaing $\left(\mathrm{X}_{2}\right)$} \\
\hline $\begin{array}{l}\text { Perusahaan selalu rekatif terhadap tindakan kompetitif } \\
\text { pesaing yang mengancam }\left(\mathrm{X}_{2,1}\right)\end{array}$ & 0,00 & 3,33 & 20,00 & 30,00 & 46,67 & 4,20 \\
\hline $\begin{array}{l}\text { Perusahaan secara teratur melakukan diskusi membahas } \\
\text { strategi pesaing }\left(\mathrm{X}_{2,2}\right)\end{array}$ & 0,00 & 3,33 & 30,00 & 36,67 & 30,00 & 3,93 \\
\hline $\begin{array}{l}\text { Perusahaan memiliki keunggulan bersaing dalam startegi } \\
\text { melawan pesaing }\left(\mathrm{X}_{2,3}\right)\end{array}$ & 0,00 & 3,33 & 10,00 & 43,33 & 43,33 & 4,27 \\
\hline $\mathrm{X}_{2}$ & & & & & & 4,13 \\
\hline \multicolumn{7}{|l|}{ Koordinasi antar fungsional $\left(\mathrm{X}_{3}\right)$} \\
\hline $\begin{array}{l}\text { Perusahaan menyebarkan informasi dari dan antar semua } \\
\text { fungsional }\left(\mathrm{X}_{3,1}\right)\end{array}$ & 0,00 & 3,33 & 20,00 & 36,67 & 40,00 & 4,13 \\
\hline $\begin{array}{l}\text { Perusahaan membentuk strategi dari koordinasi antar } \\
\text { fungsional }\left(\mathrm{X}_{3,2}\right)\end{array}$ & 0,00 & 0,00 & 20,00 & 40,00 & 40,00 & 4,20 \\
\hline $\begin{array}{l}\text { Perusahaan memahami setiap karyawan bias berkontribusi } \\
\text { untuk menciptakan nilai bagi pelanggan }\left(\mathrm{X}_{3,3}\right)\end{array}$ & 0,00 & 3,33 & 16,67 & 36,67 & 43,33 & 4,20 \\
\hline $\mathrm{X}_{3}$ & & & & & & 4,18 \\
\hline Total & & & & & & 4,16 \\
\hline
\end{tabular}

Sumber: Data diolah, 2017

Tabel 5 menunjukkan rata-rata skor pada variabel orientasi pasar adalah 4,16. Hasil tersebut termasuk dalam kategori baik. Skor rata-rata tertinggi dimiliki indikator koordinasi antar fungsional pada dimensi perusahaan membentuk strategi dari koordinasi antar fungsioal $\left(\mathrm{X}_{3.2}\right)$ dan perusahaan 
memahami setiap karyawan bisa berkomunikasi untuk menciptakan nilai bagi pelanggan $\left(\mathrm{X}_{3.3}\right)$. Sebesar 40 persen responden sangat setuju dan 40 persen responden setuju bahwa perusahaan membentuk strategi dari koordinasi antar fungsional pada UMKM Pie Susu. Responden sangat setuju bahwa perusahaan memahami setiap karyawan bisa berkomunikasi untuk menciptakan nilai bagi pelanggan pada UMKM Pie Susu sebesar 43,33 persen dan 36,67 persen responden lainnya setuju.
Skor rata-rata terendah terdapat pada indikator orientasi pesaing tepatnya pada dimensi perusahaan secara teratur melakukan diskusi membahas strategi pesaing $\left(\mathrm{X}_{2.2}\right)$. Sebesar 36,67 persen responden setuju dan 30,00 persen responden lainnya sangat setuju dan netral.

Inovasi produk sebagai variabel intervening diukur dengan menggunakan 6 indikator. Hasil dari pengukuran variabel inovasi produk disajikan dalam Tabel 6 sebagai berikut.

Tabel 6 Penilaian Responden Terhadap Variabel Inovasi Produk

\begin{tabular}{lccccccc}
\hline \multirow{2}{*}{ Indikator } & \multicolumn{4}{c}{ Distribusi } & \multicolumn{2}{c}{ Jawaban $(\%) ; \mathrm{n}=30$} & \multicolumn{2}{c}{ Rata-Rata } \\
\cline { 2 - 6 } & 1 & 2 & 3 & 4 & 5 & Skor \\
\hline Packing desain produk $\left(\mathrm{Y}_{1,1}\right)$ & 0,00 & 0,00 & 6,67 & 30,00 & 63,33 & 4,57 \\
Penambahan varian produk $\left(\mathrm{Y}_{1,2}\right)$ & 0,00 & 6,67 & 20,00 & 43,33 & 30,00 & 3,97 \\
Penambahan fitur varian produk $\left(\mathrm{Y}_{1,3}\right)$ & 0,00 & 10,00 & 10,00 & 30,00 & 50,00 & 4,20 \\
Kontrol kualitas $\left(\mathrm{Y}_{1,4}\right)$ & 0,00 & 0,00 & 26,67 & 30,00 & 43,33 & 4,17 \\
Standar kualitas $\left(\mathrm{Y}_{1,5}\right)$ & 0,00 & 0,00 & 16,67 & 43,33 & 40,00 & 4,23 \\
Pengembangan kualitas $\left(\mathrm{Y}_{1,6}\right)$ & 0,00 & 0,00 & 30,00 & 33,33 & 36,67 & 4,07 \\
\hline
\end{tabular}

Sumber: Data diolah, 2017

Tabel 6 menunjukkan rata-rata skor pada variabel inovasi produk adalah 4,20. Hasil tersebut termasuk dalam kategori sangat baik. Skor rata-rata tertinggi dimiliki indikator packaging desain produk UMKM Pie Susu $\left(\mathrm{Y}_{1.1}\right)$ sebesar 4,57. Responden yang sangat setuju sebesar 63,33 persen dan 30,00 persen responden setuju. Skor rata-rata terendah terdapat pada indikator penambahan varian produk
UMKM Pie Susu $\left(\mathrm{Y}_{1.2}\right)$ sebesar 3,97 dengan 43,33 persen responden setuju dan 30,00 persen responden lainnya sangat setuju.

Kinerja pemasaran sebagai variabel dependent diukur dengan menggunakan 4 indikator. Hasil dari pengukuran variabel kinerja pemasaran disajikan dalam Tabel 7 sebagai berikut.

Tabel 7 Penilaian Responden Terhadap Variabel Kinerja Pemasaran

\begin{tabular}{|c|c|c|c|c|c|c|}
\hline \multirow{2}{*}{ Indikator } & \multicolumn{5}{|c|}{ Distribusi Jawaban $(\%) ; \mathrm{n}=30$} & \multirow{2}{*}{$\begin{array}{c}\text { Rata-Rata } \\
\text { Skor }\end{array}$} \\
\hline & 1 & 2 & 3 & 4 & 5 & \\
\hline Pertumbuhan penjualan $\left(\mathrm{Y}_{2,1}\right)$ & 0,00 & 3,33 & 20,00 & 30,00 & 46,67 & 4,20 \\
\hline Volume penjualan $\left(\mathrm{Y}_{2,2}\right)$ & 0,00 & 13,33 & 23,33 & 43,33 & 20,00 & 3,70 \\
\hline Return of asset $\left(\mathrm{Y}_{2,3}\right)$ & 0,00 & 0,00 & 26,67 & 40,00 & 33,33 & 4,07 \\
\hline Pertumbuhan pelanggan $\left(\mathrm{Y}_{2,4}\right)$ & 0,00 & 3,33 & 23,33 & 30,00 & 43,33 & 4,13 \\
\hline \multicolumn{6}{|l|}{ 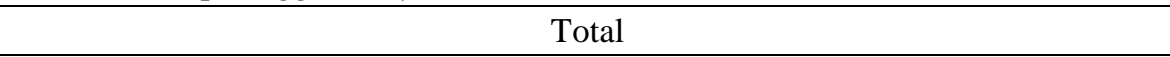 } & 4,03 \\
\hline
\end{tabular}

Sumber: Data diolah, 2017

Tabel 7 menunjukkan rata-rata skor pada variabel kinerja pemasaran adalah 4,20. Hasil tersebut termasuk dalam kategori sangat baik. Skor rata-rata tertinggi dimiliki indikator pertumbuhan penjualan $\left(\mathrm{Y}_{2.1}\right)$. Sebesar 46,6 persen responden sangat setuju dan 30 persen setuju bahwa pertumbuhan penjualan UMKM Pie Susu. Indikator volume penjualan UMKM Pie Susu memiliki skor rata-rata terendah sebesar 3,70 dengan 43,33 persen responden setuju dan 23,33 persen responden netral. Hasil tabulasi data selanjutnya akan diolah menggunakan analisi jalur. Hasil analisi jalur disajikan pada Tabel 8 dan Tabel 9.

Berdasarkan olahan data di dalam Tabel 8 dapat dirumuskan persamaan struktural untuk hipotesis 1 adalah sebagai berikut.

$\mathrm{Y}_{1}=0,861 \mathrm{X}+e_{1}$. 
Tabel 8 Hasil Analisis Jalur Persamaan Regresi 1

\begin{tabular}{llccccc}
\hline \multirow{2}{*}{ Model } & \multicolumn{2}{c}{$\begin{array}{c}\text { Unstandardized } \\
\text { Coefficients }\end{array}$} & \multicolumn{2}{c}{$\begin{array}{c}\text { Standardized } \\
\text { Coefficients }\end{array}$} & & \\
\cline { 3 - 6 } & & $\mathrm{B}$ & Standrant Eror & Beta & $\mathrm{T}$ & Sig. \\
\hline 1 & (Constant) & 0,472 & 0,421 & & 1,122 & 0,271 \\
& Orientasi Pasar & 0,897 & 0,100 & 0,861 & 8,955 & 0,000 \\
\hline $\mathrm{R}_{1}{ }^{2}$ & $: 0,741$ & & & & & \\
F Statistik & $: 80,199$ & & & & \\
Sig. F & $: 0,000$ & & & & \\
\hline
\end{tabular}

Sumber: Data diolah, 2017

Berdasarkan data di dalam Tabel 9 dapat dirumuskan persamaan struktural untuk hipotesis 2 dan 3 adalah sebagai berikut. $\mathrm{Y}_{2}=0,594 \mathrm{X}+0,388 \mathrm{Y}_{1}+e_{2}$
Persamaan regresi 1 dan regresi 2, diketahui nilai dari $\mathbf{R}_{1}^{2}=0,741$ dan $\mathbf{R}_{2}{ }^{2}=0,899$. Standard error (e) telah dihitung, maka didapatkan hasil pengaruh error $_{1}\left(e_{1}\right)$ adalah 0,715 dan pengaruh error ${ }_{2}\left(e_{2}\right)$

Tabel 9 Hasil Analisis Jalur Persamaan Regresi 2

\begin{tabular}{|c|c|c|c|c|c|c|}
\hline & \multirow[t]{2}{*}{ Model } & \multicolumn{2}{|c|}{ Unstandardized Coefficients } & \multirow{2}{*}{$\begin{array}{c}\text { Standardized } \\
\text { Coefficients }\end{array}$} & \multirow[b]{2}{*}{$\mathrm{t}$} & \multirow[b]{2}{*}{ Sig. } \\
\hline & & $\mathrm{B}$ & Standart Eror & & & \\
\hline \multirow[t]{3}{*}{1} & (Constant) & 0,635 & 0.303 & & 2,092 & 0,046 \\
\hline & Orientasi Pasar & 0,686 & 0,139 & 0,594 & 4,944 & 0,000 \\
\hline & Inovasi Produk & 0,430 & 0,133 & 0,388 & 3,232 & 0,003 \\
\hline $\mathrm{R}_{2}{ }^{2}$ & 0,899 & & & & & \\
\hline F Statistik & $: 120,574$ & & & & & \\
\hline Sig. F & $: 0,000$ & & & & & \\
\hline
\end{tabular}

Sumber: Data diolah, 2017

adalah 0,582. Koefisien determinasi total memiliki nilai 0,974 yang berarti bahwa, sebesar 97,4 persen dari variabel kinerja pemasaran dipengaruhi oleh variabel orientasi pasar dan variabel inovasi produk, sedangkan 2,6 persen sisanya dipengaruhi oleh faktor lain di luar model.

Tabel 10 Pengaruh Langsung, Pengaruh Tidak Langsung, dan Pengaruh Total Orientasi Pasar $(X)$, Inovasi Produk $\left(Y_{1}\right)$, Kinerja Pemasaran $\left(\mathbf{Y}_{2}\right)$

\begin{tabular}{cccc}
\hline $\begin{array}{c}\text { Pengaruh } \\
\text { Variabel }\end{array}$ & $\begin{array}{c}\text { Pengaruh } \\
\text { Langsung }\end{array}$ & $\begin{array}{c}\text { Pengaruh Tidak langsung Melalui Inovasi } \\
\text { Produk } \\
(\mathrm{M})=\left(\beta_{1} \times \beta_{3}\right)\end{array}$ & $\begin{array}{c}\text { Pengaruh } \\
\text { Total }\end{array}$ \\
\hline $\mathrm{X} \rightarrow \mathrm{Y}_{1}$ & 0,861 & - & 0,861 \\
$\mathrm{X} \rightarrow \mathrm{Y}_{2}$ & 0,594 & 0,334 & 0,928 \\
$\mathrm{Y}_{1} \rightarrow \mathrm{Y}_{2}$ & 0,388 & - & 0,388 \\
\hline
\end{tabular}

Sumber: Data diolah, 2017

Tabel 10 menunjukkan orientasi pasar memiliki pengaruh langsung terhadap inovasi produk sebesar 0,861 . Sebesar 0,594 adalah pengaruh langsung dari orientasi pasar terhadap kinerja pemasaran dan sebesar 0,334 merupakan pengaruh tidak langsung, sehingga memiliki pengaruh total sebesar 0,928 . Inovasi produk berpengaruh langsung terhadap kinerja pemasaran sebesar 0,388. Berasarkan hasil perhitungan nilai $Z$ dari uji Sobel adalah 2,764 atau lebih besar dari 1,96. Sehingga inovasi produk signifikan memediasi pengaruh orientasi pasar terhadap kinerja pemasaran UMKM Pie Susu di Kota Denpasar.

$$
\begin{aligned}
& \mathrm{Z}=\frac{a b}{\sqrt{b^{2} s a^{2}+a^{2} s b^{2}+s a^{2} s b^{2}}} \\
& (0,861)(0,388)
\end{aligned}
$$

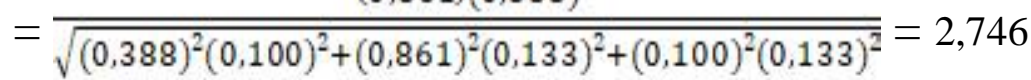


Hasil pengujian menunjukkan hubungan orientasi pasar terhadap inovasi pasar memiliki koefisien beta sebesar 0,861 dengan tingkat signifikansi sebesar 0,000 atau lebih kecil dari 0,05, sehingga $\mathrm{H}_{1}$ akan diterima dan $\mathrm{H}_{0}$ akan ditolak. Nilai tersebut membuktikan orientasi pasar berpengaruh positif dan signifikan terhadap inovasi produk pada UMKM Pie Susu di Kota Denpasar. Hal ini dapat diartikan semakin baik UMKM Pie Susu di Kota Denpasar melakukan orientasi pasar yang ditunjukkan oleh orientasi pelanggan, orientasi pesaing, dan koordinasi anatar fungsional maka inovasi produk akan meningkat, begitu pula sebaliknya. Penelitian ini juga sejalan dengan beberapa penelitian yang dilakukan oleh Zhang dan Yanling (2010), Jabeen et al. (2013), Subroto (2013), Putri, dkk (2016), Haryanto dkk. (2017) dan Widyantara (2017) menunjukkan bahwa orientasi pasar berpengaruh positif dan signifikan terhadap inovasi produk.

Hubungan orientasi pasar terhadap kinerja pemasaran memiliki koefisien beta 0,594 dengan signifikansi sebesar 0,000 atau lebih kecil dari 0,05, sehingga $\mathrm{H}_{2}$ diterima dan $\mathrm{H}_{0}$ ditolak. Nilai tersebut memiliki arti semakin baik UMKM Pie Susu di Kota Denpasar melakukan orientasi pasar yang ditunjukkan oleh orientasi pelanggan, orientasi pesaing dan koordinasi antar fungsional maka kinerja pemasaran akan meningkat, begitu pula sebaliknya. Hasil penelitian ini sejalan dengan penelitian yang dilakukan oleh Bakti dan Harniza (2011) Ahimbisibwe et al. (2013), Anggraini dkk. (2014), Nur et al. (2014), dan Zainul et al. (2016) serta tidak sejalan dengan penelitian yang dilakukan oleh Sumiati (2015) bahwa orientasi pasar tidak berpengaruh positif dan signifikan terhadap kinerja pemasaran.

Hasil pengujian menunjukkan hubungan inovasi produk terhadap kinerja pemasaran memperoleh koefisien beta sebesar 0,388 dengan nilai signifikansi sebesar 0,003 atau lebih kecil dari 0,05, sehingga $\mathrm{H}_{3}$ diterima dan $\mathrm{H}_{0}$ ditolak. Nilai tersebut membuktikan inovasi produk berpengaruh positif dan signifikan terhadap kinerja pemasaran. Hasil perhitungan ini memiliki arti, semakin baik UMKM Pie Susu di Kota Denpasar melakukan inovasi produk yang ditunjukkan oleh packaging desain produk, penambahan varian produk, penambahan fitur varian produk, kontrol kualitas, standar kualitas, dan pengembangan kualitas maka kinerja pemasaran akan meningkat, begitu pula sebaliknya saat UMKM Pie Susu tidak dapat melakukan inovasi produk dengan baik maka kinerja pemasaran akan menurun. Penelitian terdahulu yang sejalan dilakukan oleh Parkman et al. (2012), Chaston dan Scoot (2012), Riyaldi dan Kerti (2016), Carvalho dan Joel (2016), Utamaningsih (2016), dan Vera dan Giantari (2016) bahwa inovasi produk berpengaruh positif dan signifikan terhadap kinerja pemasaran, dan tidak sejalan dengan penelitian yang dilakukan oleh Quantsnanda dan Bambang (2015).

Hasil pengujian menunjukkan nilai $\mathrm{Z}$ pada uji Sobel sebesar 2,746 atau lebih besar dari 1,96, sehingga $\mathrm{H}_{4}$ diterima dan $\mathrm{H} O$ ditolak. Hal ini berarti inovasi produk mampu memediasi secara penuh pengaruh orientasi pasar terhadap kinerja pemasaran UMKM Pie Susu di Kota Denpasar. Semakin baik inovasi produk maka pengaruh orientasi pasar terhadap peningkatan kinerja pemasaran semakin besar, begitu pula sebaliknya. Hasil penelitian ini didukung oleh beberapa penelitian terdahulu dari Theohararkis dan Hooley (2008), Jhonson et al. (2009), Putri dkk. (2016) yang menyatakan bahwa inovasi produk mampu memediasi secara penuh pengaruh orientasi pasar terhadap kinerja pemasaran.

Hasil penelitian ini memiliki implikasi teoritis dan praktis. Secara teoritis penelitian ini menunjukkan pengaruh positif dan signifikan dari orientasi pasar terhadap inovasi produk dan kinerja pemasaran serta inovasi produk yang berpengaruh positif dan signifikan terhadap kinerja pemasaran. Penelitian ini juga menunjukkan inovasi produk mampu memediasi secara signifikan orientasi pasar dan kinerja pemasaran UMKM Pie Susu di Kota Denpasar. Oleh karena itu, penelitian ini dapat menambah kajian empiris dan memperkuat penelitian sebelumnya bahwa saat perusahaan ingin meningkatkan kinerja pemasaran perlu didukung dengan adanya orientasi pasar dan inovasi produk. Penelitian ini memiliki beberapa keterbatasan. Pertama, ruang lingkup penelitian ini hanya pada UMKM Pie Susu di Kota Denpasar. Oleh karena itu, hasil penelitian ini tidak dapat digeneralisasikan untuk UMKM jenis lain dan berada di daerah selain Kota Denpasar. Kedua, dilakukan pada satu kurun waktu tertentu saja (cross section), sedangkan lingkungan bersifat sangat dinamis sehingga diharapkan penelitian ini dapat dilakukan kembali di masa mendatang.

\section{SIMPULAN DAN SARAN}

Berdasarkan pembahasan yang telah dipaparkan diatas penelitian ini memiliki beberapa 
simpulan. Pertama, orientasi pasar berpengaruh positif dan signifikan terhadap inovasi produk. Berarti semakin baik UMKM Pie Susu di Kota Denpasar melakukan orientasi pasar maka inovasi produk akan meningkat, begitu pula sebaliknya. Kedua, orientasi pasar berpengaruh positif dan signifikan terhadap kinerja pemasaran. Berarti semakin baikUMKM Pie Susu di Kota Denpasar melakukan orientasi pasar maka kinerja pemasaran akan meningkat, begitu pula sebaliknya. Ketiga, inovasi produk berpengaruh positif dan signifikan terhadap kinerja pemasaran. Berarti semakin baik UMKM Pie Susu di Kota Denpasar melakukan inovasi produk maka kinerja pemasaran akan meningkat, begitu pula sebaliknya. Keempat, novasi produk berperan dalam memediasi secara penuh pengaruh orientasi pasar terhadap kinerja pemasaran. Berarti semakin baik UMKM Pie Susu di Kota Denpasar melakukan inovasi produk maka pengaruh orientasi pasar terhadap kinerja pemasaran semakin besar, begitu pula sebaliknya.

Berdasarkan hasil dan kesimpulan penelitian, maka ada beberapa saran yang dapat berikan. Pertama, hasil penelitian menunjukkan perlu adanya peningkatan pada aspek orientasi pesaing khususnya pada bagian pembahasan strategi pesaing dengan secara rutin melakukan evaluasi bulanan mengenai perkembangan penjualan, sehingga orientasi pasar dari UMKM Pie Susu di Kota Denpasar dapat lebih ditingkatkan. Kedua, pemilik atau manajer dari UMKM Pie Susu di Kota Denpasar juga disarakan meningkatkan aspek penambahan varian produk seperti penambahan rasa-rasa otentik khas Bali maupun ukuran yang lebih beragam, sehingga termasuk dalam indikator inovasi produk, sehingga pengaruh orientasi pasar terhadap kinerja pemasaran dapat lebih ditingkatkan sesuai dengan hasil penelitian yag telah dilakukan.

\section{REFERENSI}

Ahimbisibwe, G. M., Joseph, M. N., and Muhammed, N. 2013. Export Market Orientation, Innovation and Perfomance of Fruit Exporting Firm in Uganda. European Scientific Journal, 9 (4), 295-313,

Atalaya, M., Anafarta, N., and Sarvanc, F. 2013. The Relationship Between Innovation and Firm Performance: an Empirical Evidence From Turkish Automotive Supplier Industry. Procedia - Social and Behavioral Sciences, 75, 226-235

Bakti, S., Harniza, H. 2011. Pengaruh Orientasui Pasar dan Nilai Pelanggan terhadap Kinerja Pemasaran Maskapai Penerbangan Lion Air.
Jurnal Manajemen Pemasaran Modern, 3 (1), $1-15$

Cahyo, R. J., dan Harjani, D. 2013. Analisis Inovasi Produk pada Sektor Usaha Formal dan Informal di Jawa Timur. AGORA, 1 (3)

Chaston, I., dan Scott, G. J. 2012. Enterpreneurship and Open Innovation in an Emerging Economy. Journal of Management Decision, 50 (7), 1161-1177,

Chuwiruch, N. 2014. Market Innovation Strategy and Market Perfomance: A Concceptual Framework. Proceedings of the Academy of Marketing Studies, 19 (2), 82-93

Dinas Perindustrian dan Perdagangan Provinsi Bali. 2015. Data Usaha Kecil dan Menengah Provinsi Bali

Hartanty, I. T., Alifah, R. 2013. Peningkatan Kinerja Pemasaran melalui Optmalisasi Keunggulan Bersaing. Jurnal Ekobis, 14 (2), 72-89

Haryanto, A. T., Tulus, H., dan Hunik, S. R. S. 2017, Market Orientation, Learning Orientation and Small Medium Enterprises Performance:The Mediating Role of Innovation. International Review of Management and Marketing, 7 (1), 484-491

Herrero, A., H. San, M., dan J. Collado. 2017. Market Orientation and SNS Adoption for Marketing Purposes in Hospitality Microenterprises. Journal of Hospitality and Tourism Management, 34, 30-40

Jabeen, R., Jamal, M. E. A., and Khaldoun, A. M. L. 2013. Antecedents of Firm'S Performance. Empirical Evidence from Yemeni Sme'S, American Journal of Economics, 3 (1), 18-22

Jhonson, A. J., Dirbell, C. C., and Hansen, E. 2009. Mar- ket Orientation, Innovativeness, and Perfor- mance of Food Companies.Journal of Agri- business 27 (2), 85-106

Jyoti, J., dan Sharma, J. 2012. Impact of Market Orientation on Business Performance: Role of Employee Satisfaction and Customer Satisfaction. Vision, 16 (4), 297-313,

Muangkhot, S., Praprukbaramee, U. 2015. Strategic Marketing Innovation and Marketing Performance: An Empirical Investigation of Furniture Exporting Businesses in Thailand. The Business and Management Review, 7(1), 189-205

Nasution, A. A. 2014. Analisis Kinerja Pemasaran PT. Alfa Scorpii Medan. Jurnal Riset Akuntansi dan Bisnis, 14 (1), 1-14

Nur, N. N., Surachman, U. S., and Djumahir. 2014. Entrepreneurship Orientation, Market Orientation, Business Strategy, Management Capabilities On 
Business Performance; Study At Small And Medium Enterprise Printing In Kendari. International Journal of Business and Management Invention, 3(12), 8-17

Ozsahin, M., Cemal, Z., A. Zafer, A., Melike, K. S. 2013. The Effects of Leadership and Market Orientation on Organizational Commitment. Procedia - Social and Behavioral Sciences, 99, $363-372$

Parkman, I. D., Holloway, S. S., and Sebastio, Helder. 2012. Creative Industries: Aligning Entrepreneurial Orientation and Innovation Capacity. Journal of Research in Marketing and Entrepreneurship, 14 (1), 95-114

Pramesti, N. M. V., dan I, G. A. K. Giantari. 2016. Peran Orientasi Pasar Memediasi Pengaruh Orientasi Kewirausahaan terhadap Kinerja UKM Industri Kain Endek. E-Jurnal Manajemen Unud, 5 (9), 5754-5782

Putri, P. I. P. P., N. N. Kerti Yasa., dan I, K. Rahyuda. 2016. The Role of Innovation in Mediating Market Orientation to Company Perfomance. Jurnal Dinamika Manajemen, 7 (2), 105-116,

Quantananda, E., Bambang, H. 2015. Pengaruh Orientasi Kewirausahaan pada Perusahaan Makanan dan Minuman di Surabaya. Jurnal Agro, 3 (1), 706-715

Rustiarini, N. W., A, A. Dwi Widyani. 2016. Pembinaan Aspek Manajemen pada Kelompok Usaha Oleh-Oleh Khas Bali. Jurnal Bakti Saraswati, 4 (2), 128-137

Ryiadi, N. A., N. Y. Kerti Yasa. 2016. Kemampuan Inovasi Memediasi Pengaruh Orientasi Kewirausahaan terhadap Kinerja Produk IMK Sektor industri Makanan di Kota Denpasar. EJurnal Manajemen Unud, 5 (3), 1915 - 1941

Subroto, A. 2013. Pengaruh Market Orientation terhadap Service Quality, Statisfiction dan Loyalty Pelanggan Toko Buku Gramedia di
Jawa Timur. Jurnal Manajemen dan Kewirausahaan. 5 (1), 41-52

Sugiyono. 2014. Metode Penelitian Bisnis (Pendekatan Kuantitatif, Kualitatif, dan $R \& D)$. Bandung: Alfabeta

Sumiati. 2015. Pengaruh Strategi Orientasi Wirausaha dan Orientasi Pasar Pengaruhnya terhadap Kinerja Perusahaan UMKM di Kota Surabaya. Jurnal Ilmu Ekonomi \& Manajemen, 1 (1), 31 - 4431

Theoharakis, V., Hooley, G. 2008. Customer Orientation and Innovativeness: Differing Roles in New and Old Europe. International Journal of Research in Marketing, 25, 69-79,

Utama, Made Suyana. 2014. Aplikasi Analisis Kuantitatif. Denpasar: CV. Sastra Utama

Utamaningsih, A. 2016. Pengaruh Orientasi Pasar, Inovasi, dan Kreativitas Strategi Pemasaran terhadap Kinerja Pemasaran pada UKM Kerajinan Rotan di Desa Teluk Wetan, Welahan, Jepara. Jurnal Media Ekonomi dan Manajemen, 31 (2), 2503-4460

Zainul, M., Endang, S. A., Zainul, A., dan Hamidah, N. U. 2016. The Effect of Market Orientation Toward Organizational Learning, Innovation, Competitive Advantage, and Corporate Performance (A Study at SME Sasirangan in South Kalimantan). Journal of Administrative Sciences and Policy Studies, 4 (1), 1-19

Zhang, J., dan Yanling Duan. 2010. Empirical Study on The Impact of Market Orientation and Innovation Orientation on New Product Performance of Chinese Manufacturers. Nankai Business Review International, 1 (2), 214-231

Zhou, K. Z., James, R. B., dan Chekitan, S. D. 2009. Market Orientation, Competitive Advantage, and Perfomance: A Demand-Based Perspective. Journal of Business Research, 662, 1063-1070 